\title{
La opinión de los usuarios en la toma de decisiones del Servicio Central de Idiomas
}

\author{
Alfredo Javier Fernández Sánchez; Chloé Hélène Signès; Claudia Toda Castán; \\ Claudia Kerstin Ruhnke; Dan Iulian Toader; Emma Jane Keck; Juan José \\ López Moro; Manuel Sentenac Merchán; María Luisa Fernández Rodríguez
}

\section{Servicio Central 1 de Idiomas}

E

L Servicio Central de Idiomas (en adelante, SCI) comenzó a realizar encuestas para conocer la opinión de sus usuarios/as en el curso académico 2001-2002, con un doble objetivo:

- Conocer su grado de satisfacción y, analizando esta información, introducir mejoras en los servicios que ofrece a la comunidad universitaria.

- Ofrecer un canal de comunicación directo con sus usuarios/as. Las aportaciones realizadas a través de esta vía se estudian y dan lugar a nuevas mejoras.

Una vez que se dispone de las respuestas a los cuestionarios correspondientes, la Unidad de Evaluación de la Calidad trata la información resultante, garantizándose así la imparcialidad en la interpretación de los resultados.

Los informes son analizados por el Equipo de Dirección del Servicio Central de Idiomas, que transmite la información a los miembros implicados de la plantilla.

El SCI se ha fijado como compromiso la publicación de los resultados generales de las encuestas de satisfacción de sus usuarios/as, que pueden consultarse en su página web.

Los resultados obtenidos con esta práctica son varios:

- Implicar a los usuarios/as en la gestión del SCI.

- Mayor implicación del personal del SCI en el desarrollo de tareas de mejora y en el trabajo diario.

- Introducir mejoras procedentes de las sugerencias recibidas.

- Transparencia en la gestión, mediante la publicación de los resultados de las encuestas. 
- Ha contribuido a la obtención de Sellos de Excelencia Europea, otorgados por agencias externas de evaluación de la calidad.

En el curso 2001-2002 el SCI solicitó a la Unidad de Evaluación de la Calidad su colaboración para la evaluación de los cursos de idiomas que imparte.

Posteriormente, la medición del grado de satisfacción se ha extendido al resto de los servicios prestados por el SCI.

Para ello se han ido creando y modificando en el tiempo unos cuestionarios organizados en los siguientes apartados:

- Valoración de la actividad realizada o los servicios prestados.

- Valoración del Servicio Central de Idiomas y el personal que lo integra.

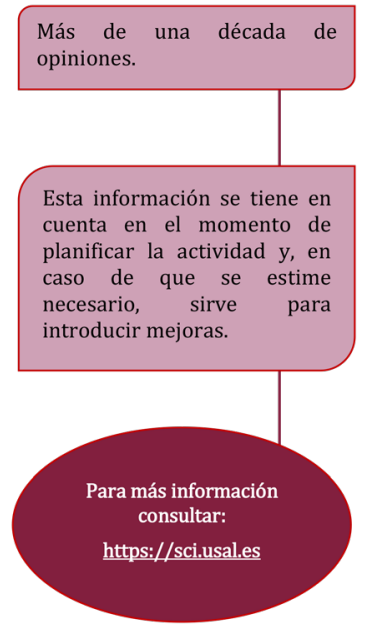

- Valoración de las instalaciones e infraestructura (si procede).

- Satisfacción general.

- Apartado de sugerencias de mejora o quejas con el que se da voz al usuario/a. 